\title{
Study on the Safety and Accuracy of Intracavitary Electrocardiography and Ultrasound in the Peripherally Inserted Central Venous Catheter tip positioning of Breast Cancer Patients
}

\author{
YAN FEI. XU, XIA FEI. XU11, KUN. SONG ${ }^{2}$, C. QIU², XIAO LI. ZHANG ${ }^{2}$, DI LI NU ER-RE HE. MAM² AND S. HUANG*
}

Department of Nursing, Nantong Tumor Hospital, Nantong, 226200, 'Department of Nursing, Nantong Third People's Hospital, Nantong, 226006, ${ }^{2}$ Nanjing Hope Medical Laboratory Co.,Ltd, Nanjing, 210001, China

Fei et al.: Safety and accuracy of intracavitary electrocardiography and ultrasound in breast cancer patients

\begin{abstract}
This study aims to explore the safety and accuracy of the intracavitary electrocardiography and ultrasound in the peripherally inserted central venous catheter tip positioning of breast cancer patients. A total of 176 breast cancer patients who were treated in the breast surgery department of our hospital from January 2018 to January 2019 were selected. They were randomly divided into the Electrocardiogram-UI group $(n=88)$ and the control group $(n=88)$. In the Electrocardiogram-UI group, the peripherally inserted central venous catheter tip positioning was under the guidance of the bedside Electrocardiogram combined with ultrasound, while the peripherally inserted central venous catheter insertion in the control group was performed by the traditional technology. The accuracy of peripherally inserted central venous catheter tip positioning, psychological state, anxiety, pain degree, and complications were compared between the two groups after surgery. The results showed that the positioning accuracy rate of the catheter tip in the Electrocardiogram-UI group was $99.40 \%$, while that in the control group was $92.10 \%$. In the control group, the accuracy rate of the catheter tip positioning in the 6th, 7th and 8th ribs was $20.30 \%, 64.10$ $\%$, and $14.70 \%$ respectively, while that in the Electrocardiogram-UI group was $32.20 \%, 40.30 \%$ and $19.60 \%$ respectively, with a significant difference between the two groups. And $24 \mathrm{~h}$ before the catheter insertion, there was no significant difference in the anxiety scores between the two groups. However, $24 \mathrm{~h}$ after the catheter insertion, the anxiety and pain scores in the Electrocardiogram-UI group were significantly lower than that of the control group. In terms of the complications, in the first $w$, two patients in the Electrocardiogram-UI group had thrombosis, while four patients in the control group. No patients had the symptoms of the chest discomfort, arrhythmia, or infection in both groups. At the end of three and six mo, the incidence of thrombosis in the Electrocardiogram-UI group was significantly lower than that of the control group. The peripherally inserted central venous catheter tip positioning technology guided by Electrocardiogram combined with ultrasound is an ideal method for peripherally inserted central venous catheter insertion. It can improve the quality of life of the breast cancer patients and promote the prognosis of the breast cancer patients.
\end{abstract}

Key words: Intracavitary electrocardiography, ultrasound, central venous catheter, tip positioning, breast cancer

The peripherally inserted central venous catheter (PICC) played an important role in the nursing of the breast cancer patients, which provided the reliable, medium-term, or long-term venous access for various clinical indications (including the safety management of the chemotherapy drugs and intravenous infusion $)^{[1]}$. Compared with the traditional central venous catheter, the PICC had the advantages of higher safety, lower infection rate, and longer retention time ${ }^{[1,2]}$. It can be used as a channel for the infusion of intravenous nutrition, chemotherapy drugs, and antibiotics ${ }^{[3,4]}$. The correct placement of the PICC tip was very important. Studies has found that the incidence of complications was only $3.8 \%$ if the tip was located in the superior 
vena cava ${ }^{[5]}$, otherwise, the incidence of complications increased to $28.8 \%$, which increased the risk of other complications, including the tip migration, infection, thrombokinase, and phlebitis ${ }^{[6,7]}$.

At present, the main technologies of PICC insertion include the blind puncture, chest X-ray technology, and ultrasound-guided Seldinger technology ${ }^{[8]}$. Recent findings show that the success rate of PICC tip localization by chest X-rays was about $80 \%$ based on conventional anatomical markers. The Seldinger technology involves the angiographic agents, which has the exposure risk to radiation. The electrocardiogram (ECG)-guided PICC tip positioning technology with the advantages of simple, no radiation exposure, and real-time adjustment ${ }^{[9]}$.

There have been some studies on the safety and effectiveness of the bedside ECG-guided PICC tip positioning for cancer patients. It is worth noting that the ECG cannot display the position of PICC tip in real-time by image, which was the main reason that restricts the application of ECG in PICC tip positioning. Therefore, this study aims to explore the effectiveness and safety of ECG combined with ultrasound in the location of the PICC tip in the breast cancer patients.

\section{CLINICAL DATA AND METHODS}

\section{Clinical data:}

A total of 186 breast cancer patients admitted to the breast surgery department of our hospital from January 2018 to January 2019 were included in this study, and all the patients signed the informed consent. Exclusion criteria: The patients with serious blood infection or systemic infection before the catheterization; The patients with compression syndrome of the superior vena cava; The patients with serious cardiovascular diseases (such as atrial fibrillation, pulmonary heart disease with abnormal $\mathrm{P}$ wave or severe heart block); Children or adolescents under 18 y old. Finally, 10 patients were excluded and 176 patients were included in this study.

The 176 patients were randomly divided into the ECGUI group $(n=88)$ and the control group $(n=88)$ by the random number table. In the ECG-UI group, the PICC tip positioning was under the guidance of the bedside ECG combined with ultrasound, while the PICC insertion in the control group was performed by the traditional technology. There was no significant difference in the age, height, weight, upper arm circumference, education level, clinical stage, complication, and history of the previous central venous catheter, history of PICC insertion, platelet count, and prothrombin time between the two groups (Table 1).

\section{Methods:}

Catheterization: The $18 \mathrm{G}(4 \mathrm{Fr}) \times 65 \mathrm{~cm} \quad \mathrm{BD}$ first PICC ${ }^{\text {TM }}$ kit was used in all patients. The catheter was inserted by the same professional nurse with the PICC qualification in an extremely closed PICC puncture room, and maintained in the hospital by the PICC nurse team. The distance from the puncture point to the right articulation sternoclavicularis plus $5-7 \mathrm{~cm}$ was the estimated catheter insertion length. The upper arm circumference was measured $10 \mathrm{~cm}$ above the elbow crease. The arm was washed and disinfected with $75 \%$ alcohol and chlorhexidine three times before the venipuncture under the guidance of ultrasound. And the vein basilar was the first choice for the venipuncture. During the operation, the length of the catheter in the body, the resistance of the guide wire removal in the catheter, and the operation time (from the incision skin disinfection to the plaster application) were recorded.

In the ECG-UI group, the signs of the patients were monitored by the limb leads of the ECG machine, the normal $\mathrm{P}$ wave and the sinus rhythm was confirmed on the leads II. When the inserted catheter reached the estimated length, the right arm lead was removed; the fixture was sterilized, and then connects it to the guide wire. Then, under the guidance of ultrasound, the guide wire was pushed slowly, $0.5-1 \mathrm{~cm}$ at a time, and the changes of the $\mathrm{P}$ wave were observed on the monitor.

During the catheter insertion, the following waveforms were obtained: The blunt short $\mathrm{P}$ wave of the normal sinus rhythm; The biphasic $\mathrm{P}$ wave indicating that the tip was located in the right atrium; The high amplitude $P$ wave indicating that the tip was located at the junction of the superior vena cava and the right atrium (the $\mathrm{P}$ wave amplitude is $80 \%$ of QRS) or the tip was located at the lower third of the superior vena cava (the $\mathrm{P}$ wave amplitude is $50 \%$ of QRS). The patients in the control group were punctured with the traditional puncture technology under the guidance of ultrasound. The $\mathrm{P}$ wave which corresponds to the depolarization of the atria begins to increase progressively as the catheter approaches the right atrium.

\section{Observation indexes:}

Radiographic examination of the chest. In order to confirm the position of the needle tip, the radiographic examination of the chest was usually regarded as the 
TABLE 1: COMPARISON OF THE CLINICAL DATA BETWEEN THE TWO GROUPS

\begin{tabular}{|c|c|c|c|}
\hline Index & ECG-UI group & Control group & $\mathrm{p}$ value \\
\hline Age & $54.62 \pm 5.70$ & $54.91 \pm 6.32$ & 0.731 \\
\hline Height $(\mathrm{cm})$ & $158.63 \pm 4.36$ & $160.21 \pm 4.77$ & 0.577 \\
\hline Weight (kg) & $58.63 \pm 4.20$ & $58.97 \pm 5.33$ & 0.787 \\
\hline Upper arm circumference $(\mathrm{cm})$ & $27.35 \pm 3.21$ & $26.89 \pm 2.88$ & 0.670 \\
\hline Education level (\%) & & & 0.634 \\
\hline Illiteracy & $11(12.50)$ & $13(14.77)$ & \\
\hline Junior middle school & $24(27.27)$ & $25(28.41)$ & \\
\hline Senior middle school/vocational high school & $35(39.77)$ & $33(37.50)$ & \\
\hline Undergraduate college and above & $18(20.46)$ & $17(19.32)$ & \\
\hline Clinical stage & & & 0.546 \\
\hline 1 & $33(37.50)$ & $35(39.78)$ & \\
\hline II & $27(30.68)$ & $26(29.54)$ & \\
\hline III & $19(21.59)$ & $18(20.45)$ & \\
\hline IV & $9(10.23)$ & $9(10.23)$ & \\
\hline Complication (\%) & & & 0.503 \\
\hline No & $74(84.09)$ & $73(82.95)$ & \\
\hline$\geq 1$ & $14(15.91)$ & $15(17.05)$ & \\
\hline History of previous central venous catheter (\%) & & & 0.577 \\
\hline Yes & $62(81.82)$ & $60(79.55)$ & \\
\hline No & $16(18.18)$ & $18(20.45)$ & \\
\hline Platelet count $\left(10^{9} / \mathrm{L}\right)$ & $228.49 \pm 78.35$ & $231.28 \pm 85.20$ & 0.530 \\
\hline Prothrombin time $(\mathrm{sec})$ & $8.83 \pm 1.21$ & $8.56 \pm 1.49$ & 0.667 \\
\hline History of PICC insertion (\%) & & & 0.513 \\
\hline Yes & $66(75.00)$ & $64(72.73)$ & \\
\hline No & $22(25.00)$ & $24(27.27)$ & \\
\hline
\end{tabular}

gold standard ${ }^{[10]}$. Therefore, the chest X-rays were performed on all patients to confirm the correct tip positions. The ideal location was defined as the lower middle third of the superior vena cava or the junction of the superior vena cava and the right atrium.

The anxiety levels before and after PICC. The state trait anxiety inventory (STAI) scale ${ }^{[11]}$ was used to evaluate the anxiety levels of the patients $24 \mathrm{~h}$ before and after the catheterization. Each item has 4 levels (1 for no anxiety, 2 for little anxious, 3 for moderate anxiety, 4 for obvious anxiety), and a total score of 20 to 80 can be used to quantify the unpleasant short-term emotional experiences $^{[12]}$.

The complications related to PICC. The complications related to PICC were recorded after $1 \mathrm{w}, 3$ mo and 6 mo in all patients who received the treatment of the catheter infusion and maintain regularly. The patients were followed up every two w to record their health and catheter conditions.

The numerical pain rating scale (NPRS) was used to evaluate the pain during the puncture. The scores of pain had four levels ( 0 for no pain, 1 to 3 for mild pain, 4 to 6 for moderate pain, 7 to 10 for severe pain).

\section{Statistical analysis:}

SPSS 20.0 software (SPSS) was used for the data analysis. The quantitative data were expressed by mean \pm standard deviation, the qualitative data were compared with Chi-square test, and the intergroup data were compared with T-test. $\mathrm{p}<0.05$ means the difference was statistically significant.

\section{Results:}

The results showed that the accuracy rate of the catheter tip positioning in the ECG-UI group was $99.40 \%$, while that in the control group was $92.10 \%(\mathrm{p}<0.05$, Table 2). In the control group, the accuracy rate of the catheter tip positioning in the 6th, 7th, and 8th ribs was $20.30 \%, 64.10 \%$, and $14.70 \%$ respectively, while that in the ECG-UI group was $32.20 \%, 40.30 \%$, and $19.60 \%$ respectively, with a significant difference between the wo groups $(p<0.05$, Table 2$)$.

During the $24 \mathrm{~h}$ before the catheter insertion, there was 
no significant difference in the anxiety scores between the two groups. However, $24 \mathrm{~h}$ after the catheter insertion, the anxiety scores in the ECG-UI group were significantly lower than that of the control group $(\mathrm{p}<0.001)$ (Table 3).

In the first w, two patients in the ECG-UI group had thrombosis, while four patients in the control group. No patients had the symptoms of the chest discomfort, arrhythmia, or infection in both groups. At the end of three and six mo, the incidence of thrombosis in the ECG-UI group was significantly lower than that of the control group ( $p=0.04, p=0.03$, Table 4).

The pain degree of the two groups was evaluated after the PICC catheter insertion, and the results showed that the NPRS scores of the ECG-UI group was significantly lower than that of the control group $(p<0.001)$ (fig. 1 and Table 5).

\section{RESULTS AND DISCUSSION}

At present, there were few comparative studies on the accuracy of different technologies of the PICC catheter tip positioning. This study showed that the accuracy of the PICC catheter tip positioning method under the guidance of ECG combined with ultrasound was better than that of the traditional method, which was consistent with other research results ${ }^{[13,14]}$. In the ECG-UI group, the catheter tip position of PICC can be adjusted in realtime by observing the shape of $\mathrm{P}$ wave and ultrasound image on the monitor. In the traditional method, the chest X-ray was used to confirm the correct tip position for the adjustment of the PICC tip. In this study, the chest X-ray was used in 11 patients in the control group

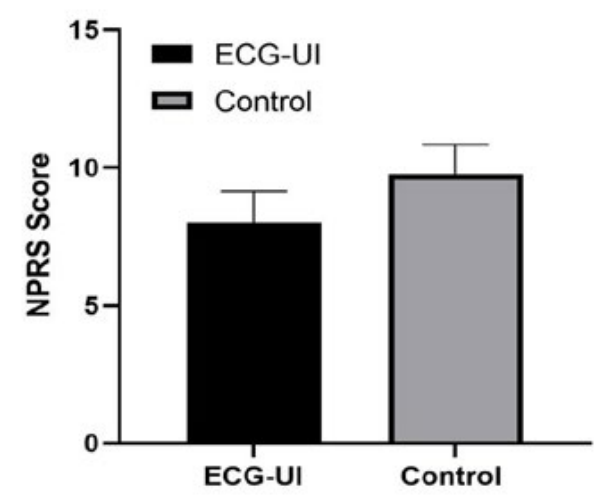

Fig. 1: Comparison of the pain degree of the two groups after the PICC catheter insertion

TABLE 2: COMPARISON OF THE ACCURACY RATE OF THE CATHETER TIP POSITIONING BETWEEN THE TWO GROUPS

\begin{tabular}{|c|c|c|c|c|c|}
\hline Groups & Total accuracy rate & $\begin{array}{l}\text { Accuracy rate of the } \\
6^{\text {th }} \text { rib }\end{array}$ & $\begin{array}{c}\text { Accuracy rate of the } \\
7^{\text {th }} \text { rib }\end{array}$ & $\begin{array}{l}\text { Accuracy rate of the } \\
8^{\text {th }} \text { rib }\end{array}$ & $p$ value \\
\hline ECG-UI Group & 99.40 & $20.30 \%$ & $64.10 \%$ & $14.70 \%$ & \multirow{2}{*}{$<0.001$} \\
\hline Control group & 92.10 & $32.20 \%$ & $40.30 \%$ & $19.60 \%$ & \\
\hline
\end{tabular}

TABLE 3: COMPARISON OF THE ANXIETY SCORES BEFORE AND AFTER THE OPERATION BETWEEN THE TWO GROUPS

\begin{tabular}{lcc}
\hline Groups & 24 $\mathrm{h}$ before the operation & 24 $\mathrm{h}$ after the operation \\
\hline ECG-UI Group & $48.25 \pm 3.55$ & $40.08 \pm 1.27$ \\
Control group & $47.83 \pm 3.73$ & $43.14 \pm 1.33$ \\
p value & 0.251 & $<0.001$ \\
\hline
\end{tabular}

TABLE 4: COMPARISON OF THE POSTOPERATIVE COMPLICATIONS IN THE SAME PERIOD BETWEEN THE TWO GROUPS

\begin{tabular}{|c|c|c|c|c|c|c|c|c|c|}
\hline \multirow[b]{2}{*}{ Complications } & \multicolumn{3}{|c|}{$1 \mathrm{w}$ after the operative } & \multicolumn{3}{|c|}{$3 \mathrm{mo}$ after the operative } & \multicolumn{3}{|c|}{$6 \mathrm{mo}$ after the operative } \\
\hline & $\begin{array}{l}\text { ECG-UI } \\
\text { group }\end{array}$ & $\begin{array}{l}\text { Control } \\
\text { group }\end{array}$ & $\mathrm{p}$ value & $\begin{array}{l}\text { ECG-UI } \\
\text { group }\end{array}$ & $\begin{array}{l}\text { Control } \\
\text { group }\end{array}$ & $\mathrm{p}$ value & $\begin{array}{l}\text { ECG-UI } \\
\text { group }\end{array}$ & $\begin{array}{l}\text { Control } \\
\text { group }\end{array}$ & $\mathrm{p}$ value \\
\hline $\begin{array}{l}\text { Mechanical } \\
\text { phlebitis }\end{array}$ & 0 & $1(1.11)$ & 0.787 & 0 & 0 & 1.000 & 0 & 0 & 1.000 \\
\hline Staxis & $10(11.36)$ & $12(13.64)$ & 0.684 & 7 (7.95) & $9(10.23)$ & 0.695 & 7 (7.95) & $8(9.09)$ & 0.688 \\
\hline Local infection & 0 & 0 & 1.000 & $2(1.14)$ & $3(3.41)$ & 0.973 & $3(3.41)$ & $4(4.54)$ & 0.98 \\
\hline Thrombosis & $2(2.27)$ & $4(4.54)$ & 0.680 & $1(2.27)$ & $8(4.54)$ & 0.021 & 0 & $6(6.82)$ & 0.023 \\
\hline
\end{tabular}

TABLE 5: COMPARISON OF THE PAIN DEGREE OF THE TWO GROUPS AFTER THE PICC CATHETER INSERTION

\begin{tabular}{lccc}
\hline Group & Cases & NPRS & P value \\
\hline ECG-Ul group & 88 & $8.01 \pm 1.12$ & $<0.001$ \\
Control group & 88 & $9.76 \pm 1.08$ & $<$ \\
\hline
\end{tabular}


for the adjustment of the PIC tip, which increased the radiation exposure to them.

Patients were anxiety during the PICC insertion ${ }^{[15]}$, and the anxiety levels were evaluated $24 \mathrm{~h}$ after PICC insertion. The anxiety levels in the ECG-UI group and the control group were $40.96 \pm 1.97,42.06 \pm 1.90$ respectively. Before the catheterization, the patients in the ECG-UI group received the positive psychological cues, which may increase the confidence to the operator and reduce their anxiety. In addition, the successful radiologic confirmation at the end of the operation can further reduce anxiety. Once the accuracy of ECG guidance technology was ensured, there was no need to have the chest X-ray examination for confirmation, which could reduce the cost of the operation. These results were consistent with the research results of Bream $^{[16]}$ and Walker ${ }^{[17]}$. In addition, there will be a certain degree of pain during the catheterization, which will also cause the emotional fluctuation of the patients. The results of this study showed that the patients in the ECG-UI group can reduce the unnecessary catheterization pain under the guidance of ultrasound and ECG, which enhanced the cooperation of the patients in the treatment.

Previous studies have shown that the complications related to PICC should be minimized as far as possible, which may affect or even interrupt the treatment of patients ${ }^{[18]}$. In this study, to ensure the safe use of PICC and reduce the complications related to PICC, all operations were performed by the experienced and skilled clinical nurses, under the strict handling rules. At the same time, some psychological counseling was given to the patients to complete the intubation successfully. In the first $\mathrm{w}$ after PICC insertion, the incidence of the complications related to the operation was lower, no patients had the symptoms of the chest discomfort, arrhythmia, or infection, and there was no significant difference between the two groups. At the end of $3 \mathrm{mo}$ and $6 \mathrm{mo}$, the cases in which the patients had the symptoms of thrombosis decreased significantly in the ECG-UI group. In the control group, the position of PICC catheter tip in some patients were adjusted repeatedly, which may damage the vein wall and lead to a higher incidence of thrombosis.

In conclusion, the PICC tip positioning technology guided by the ECG combined with ultrasound is considered as an ideal method for PICC insertion. Compared with the traditional PICC intubation technology, this method has the advantages of locating precisely, adjust the catheter tip of PICC in realtime, and avoid the radiation exposure. Meanwhile, the anxiety levels and pain scores of the patients after operation were reduced significantly, and the postoperative complications also reduce significantly. The application of the PICC tip positioning technology guided by ECG combined with ultrasound can improve the prognosis and quality of life of the patients after operation, which is worthy of clinical promotion.

\section{Acknowledgements:}

This work was supported by the Nanjing Hope Medical Laboratory Co., Ltd, (NO:2020HP1080).

\section{Conflict of interests:}

The authors declared no conflict of interest.

\section{REFERENCES}

1. Morano SG, Latagliata R, Girmenia C, Massaro F, Berneschi P, Guerriero A, et al. Catheter-associated bloodstream infections and thrombotic risk in hematologic patients with peripherally inserted central catheters (PICC). Support Care Cancer 2015;23:3289-95.

2. Dale M, Higgins A, Carolan-Rees G. Sherlock $3 C^{\circledR}$ tip confirmation system for placement of peripherally inserted central catheters: a NICE medical technology Guidance. Appl Health Econ Health Policy. 2016;14:41-9.

3. Leung A, Heal C, Banks J, Abraham B, Capati G, Pretorius C, et al. The incidence of peripheral catheter-related thrombosis in surgical patients. Thrombosis 2016;2016:6043427

4. Zhao R, Chen C, Jin J, Sharma K, Jiang N, Shentu Y, et al. Clinical evaluation of the use of an intracardiac electrocardiogram to guide the tip positioning of peripherally inserted central catheters. Int J Nurs Pract 2016;22:217-23.

5. Zhou L, Xu H, Liang J, Xu M, Yu J. Effectiveness of intracavitary electrocardiogram guidance in peripherally inserted central catheter tip placement in neonates. J Perinat Neonatal Nurs 2017;31:326-31.

6. Zhou LJ, Xua HZ, Xu MF, Hu Y, Lou XF. An accuracy study of the intracavitary electrocardiogram (IC-ECG) guided peripherally inserted central catheter tip placement among neonates. Open Med 2017;12:125-30.

7. Elli S, Cannizzo L, Marini A, Porcarelli S, Azzarone F, Fumagalli $\mathrm{R}$, et al. Catheter tip placement during PICC implantation: retrospective analysis of the reliability of the ECG method vs. radiological control. Assist Inferm Ric 2016;35:174-9.

8. Rossetti F, Pittiruti M, Lamperti M, Graziano U, Celentano D, Capozzoli G. The intracavitary ECG method for positioning the tip of central venous access devices in pediatric patients: results of an Italian multicenter study. J Vasc Access 2015;16:137-43.

9. Johnston AJ, Bishop SM, Martin L, See TC, Streater CT. Defining peripherally inserted central catheter tip position and an evaluation of insertions in one unit. Anaesthesia 2013;68:484-91.

10. Oliver G, Jones M. ECG or X-ray as the 'gold standard' for establishing PICC-tip location?. Br J Nurs 2014;23:10-16. 
11. Wang D, Niu F, Gao H, Yu M, Li Y, Xu L, et al. Influence of guide wire removal on tip location in peripherally inserted central catheters (PICCs): a retrospective cross-sectional study. BMJ Open 2019;9(10):e027278.

12. Song J, Wang C, Hu J E. Meta-Analysis of Atrial ElectroGram Applied to PICC Catheter Tip Positioning. Acad Med 2017;1:65-76.

13. Liu G, Hou W, Zhou C, Yin Y, Lu S, Duan C, et al. Metaanalysis of intracavitary electrocardiogram guidance for peripherally inserted central catheter placement. J Vas Access 2019;20:577-82.

14. Wenyan $\mathrm{P}$, Jianwen $\mathrm{S}$, Xinfang $\mathrm{X}$. Intracavitary eletrocardiogram localization of valved PICC in breast cancer patients: a comparison of two methods. Chin Remed Clin 2019.

15. Nicholson J, Davies L. Patients experiences of the PICC insertion procedure. Br J Nurs 2013;22:16-23.

16. Bream PR, Gu E. Use of an ECG-based confirmatory technique for bedside placement of reverse-tunneled cuffed dialysis catheters in three morbidly obese patients. Kidney Int 2015;88:633-6.

17. Walker G, Chan RJ, Alexandrou E, Webster J, Rickard C. Effectiveness of electrocardiographic guidance in CVAD tip placement. Br J Nurs 2015;24:4-12.

18. Nolan ME, Yadav H, Cawcutt KA, Cartin-Ceba R. Complication rates among peripherally inserted central venous catheters and centrally inserted central catheters in the medical Intensive Care Unit. J Crit Care 2016;31:238-42.

This is an open access article distributed under the terms of the Creative Commons Attribution-NonCommercial-ShareAlike 3.0 License, which allows others to remix, tweak, and build upon the work non-commercially, as long as the author is credited and the new creations are licensed under the identical terms

This article was originally published in a special issue, "Clinical Research in Pharmaceutical and Biomedical Sciences" Indian J Pharm Sci 2021:83(1)Spl issue1;6-11 